\title{
Models for Online Grocery Shopping - A Study of Pakistani Online Market
}

\author{
Sanober Ali, Mariam Saleem, Mohammad Ekhlaque Ahmed, Marium Mateen Khan, \\ Neha Shah and Saad Rafiq
}

Institute of Business Management, Karachi, Pakistan

Correspondence should be addressed to: Ekhlaque Ahmed; ekhlaque.ahmed@iobm.edu.pk

Received date: 26 September 2016; Accepted date: 14 December 2016; Published date: 3 February 2017

Academic Editor: Lai Kim Piew

Copyright (C) 2017. Sanober Ali, Mariam Saleem, Mohammad Ekhlaque Ahmed, Marium Mateen Khan, Neha Shah and Saad Rafiq. Distributed under Creative Commons CC-BY 4.0

\begin{abstract}
This research study aims at learning which type of business models is applicable for online grocery shopping in Pakistan. Qualitative research methodology has been used for the purpose of this research. Through extensive literature review a conceptual framework has been devised. It was found that there are four types of online shopping models. Out of these four any one of the business models can be used by a startup firm depending on the resources and expertise available to them. It is concluded that, Startups like Cart.pk, RashanLelo, AaramShop.pk, and Taza Mart entered the Pakistan market with considerable experience and distinctive business model. Though in Pakistan none of them has emerged as the clear winner but these startups have surely made their presence felt. Reason being, all the ventures are of already established players, with good budgets, strong sense of consumer habits and also the goodwill of their Parent company. Different models discussed in this paper lend an understanding and technicalities to the people aiming to start their own online venture. The paper also provides different models having different resources with their success elements.
\end{abstract}

Keywords: online shopping, grocery shopping, new startups, online shopping business models

\section{Background of the Study}

Traditionally it is believed and practiced that a fancy store will attract more consumers and hence will generate more sales. However, in the current era, even the concept of having a retail store chain has come under scrutiny. The world is moving towards digital space and the new markets exist online. Ecommerce market has expanded over the past years (Statistica, 2016; U.S. Census Bureau News, 2016).

Cite this Article as: Sanober Ali, Mariam Saleem, Mohammad Ekhlaque Ahmed, Marium Mateen Khan, Neha Shah and Saad Rafiq (2017)," Models for Online Grocery Shopping - A Study of Pakistani Online Market", Journal of Internet and e-Business Studies, Vol. 2017 (2017), Article ID 839022, DOI: 10.5171/2017. 839022 
The worldwide expansion of the internet has brought a transformation in the e-commerce market. E-commerce statistics show that 40 percent of the worldwide internet user population has had an online shopping experience, which means that there are more than 1 billion online buyers currently present and this population is expected to grow continuously. According to popular ecommerce market data, Amazon a US based e-commerce website is the market leader in this area. Furthermore it was seen that in 2005 , retail e-commerce sales totaled to an amount of 1.67 trillion US dollars which is predicted to grow to 3.55 trillion US dollars by 2019 (Statistica, 2016).

The e-commerce market has recently emerged and progressed at an astonishing rate. According to Ahmed, (2015), the ecommerce industry is flourishing throughout the Asian region. Flip kart an Indian ecommerce website is currently raising US $\$ 1$ billion in investment and Alibaba, China's ecommerce website, has a market capitalization of over US $\$ 250$ billion.

Pakistan's population having an access to the Internet is limited to around 30 million users. This too is expected to increase up to 56 million users by 2019. Over the next 5 years, 28 per cent of the country's population is estimated to have internet access. Furthermore, Ahmed, (2015) reports that 73.2 per cent of the entire population in Pakistan also has access to mobile phones hence facilitating the growing trend of online shopping. These statistics indicate a new horizon of opportunities for the online shopping startups.

\section{Problem statement}

Pakistan is one of the emerging e-commerce markets in the world which is increasingly moving towards online shopping. Pakistan's $60 \%$ of the population is youth aspiring to start their own business. These online ventures are expanding and increasing their scope of offerings to cater for the need of this developing market. Since this market is in its introductory stage, successful business model for this market is yet to be seen. For a venture like online grocery, the best possible business model that will lead to early breakeven and revenue generation for the startup needs to be unraveled (Arshad, 2015).

\section{Scope of Research}

Online grocery shopping is on the rise in Pakistan and has a great potential to grow. The market share of online grocery startups in Pakistan is $\$ 25$ million (Arshad, 2015). Pakistan's e-commerce market is expected to reach over US\$600 million by 2017. Pakistan's internet reach is around 30 million users, which is expected to reach around 56 million users by 2019 (Ahmed, 2015). New startups are tapping into online grocery business realizing that Pakistan is rapidly moving towards the digital space.

This rapid boom the in online market has brought out a new market segment for startups selling grocery online and changing the dynamics of the entire market. This research paper would help online grocery ventures to devise their strategies in selecting a competitive business model and to tap into the new market segments successfully.

\section{Literature Review}

The literature review provides the insight of the conventional and contemporary style of grocery retail market globally. It provides us with the knowledge of the kind of business models that currently exist for e-grocers, the changing trends in the market over time; the operational models to be followed regarding how to manage the inventory and supply chain. In future buying would be about providing unique experiences regardless of the channel (online/offline) being used. There are many disruptions faced by the retailers with the evolution of online grocery which are discussed below:

\section{Disruption 1: The Changing Role of the Store}


From the product point of view, in a store, customer can touch, feel and physically see the products. From people's experience point of view, in a store, people enjoy the entire experience of going out for shopping and the return is easy but the timing is specific. While in case of online shopping one can shop at any hour of the day, get better deals, can compare deals, have greater variety to choose from and do not have to travel.

Certain challenges of in store include: elderly buyers in the target audience are not technologically advanced, there is a lot of competition and everyone is trying to serve better than the other, window shopping has decreased and online grocers have low prices to cater a greater chunk in order to attract more customers. There are two important concepts to be kept in mind when talking about buying online: firstly, show rooming i.e. see the products in store and buy online; and the second is of reverse nature, show rooming,- where one sees the products online and purchases them from the store because buyers can immediately take product in hand (Retail \& Survey, 2015)

\section{Disruption 2: Mobile and Related Technologies}

The usage of mobile phone has increased tremendously in the last decade hence increasing the sales of mobile phones. Nowadays almost everyone has a mobile phone, making it a crucial shopping agent in the online shopping world, as it helps in buying at a touch and also for connecting and receiving feedback from the customers, retailers and the suppliers. Some people use their mobile phones to search for best deals being offered at lowest rates. But the major issue of using a mobile phone for online shopping is to make online payments. People fear that their personal and credit card information might be misused (Retail \& Survey, 2015).

\section{Disruption 3: The Proliferation of Social Networks}

According to Retail \& Survey, (2015), social media have linked the people with their favorite brands. People are more updated with the deals, sales offers and promotions being offered by various brands. Furthermore, online selling has helped the sellers in being able to post new variants of their products online on frequent basis, which has enabled them to compete with the competition in real time, knowing what the competition is offering to attract the customers, help in gaining customer feedback and finding out about customer experience.

Online interaction of consumers with the brand in real time creates emotional connection and the ease of this mode of interaction maintains consumer contact with the brand. It is therefore important for all brands or businesses dealing online to have knowledge of search engine optimization, directing traffic to website, creating a dialogue and spreading word of mouth. In the online world it is more about firstly building a relationship with the consumers and then selling the product. Online businesses need to optimize their reach by using different social media platforms and should not stick to only one platform. Most commonly used platforms these days include Facebook, Google Plus, Twitter, LinkedIn, Instagram, Pinterest, Whatsapp etc. (Retail \& Survey, 2015).

Success of an e-commerce website is partially because of the design and interface through which the retailer provides its customers with the offers. A user friendly interface being a part of online shopping model helps the customers to browse the website and search for their desired products with ease, this initiates the purchase and likeability of the e-retailer by the customers (Hong, Thong, \& Tam, 2004).

\section{Disruption 4: Demographics}

People falling in the age group of 18-24 are more inclined towards the use of digital space and devices. They are known as the Digital Natives and are more inclined 
towards the use of internet to carry out many of their routine tasks. It is seen that they shop more after being connected to their favorite brand online (Retail \& Survey, 2015).

\section{Models for Online Grocers - Two Broad Business Models}

There are two types of business models that can be used for e- grocers globally. Both models have seen successes and failures in different scenarios, factors and resources, suggesting that either can be used depending on the appropriate mix of pertinent factors. The factors include; customer density, management, logistics and distribution, order picking and order fulfillment, and customer retention (Zott, Amit, \& Massa, 2011).

The two tried and tested models for egrocers are:

1. Brick \& Mortar and Store-pick Model: this model is typically followed by those companies which either have existing stores, like Tesco, or those which have paired with supermarkets. These companies use existing supermarkets to collect orders and then deliver them according to the delivery system being followed. This model relatively has a low cost since there are no additional warehouse costs, and the goods are easily available at the supermarket the company has paired with.

2. Pure play and Warehouse-pick Model: this model is relatively expensive as it involves independent companies which do not have any existing brick and mortar stores. In this model, companies buy directly from producers/manufacturers, and operate their own warehouses where they stock the products. An example is FreshDirect.

3. Hybrid Model: This model combines elements from the above two models. For example, Peapod in the US is a pure play company, with no stores of its own. However, it has paired with existing supermarkets like Safeway in Chicago from where it picks orders and delivers to customers.

Online shopping provides the customers with many facilities like ordering directly from home or office, without any hassle. The online website also remembers the customers' previous selections from past shopping and adds them to the favorite list hence saving customers' time. Online retailers also make suggestions to the customers based on their past shopping patterns and enable the selection of new product purchase. However, in online shopping the quality of the product being purchased cannot be inferred and the risk on customers' side increases (Pozzi, 2012; Pozzi, 2013).

\section{Business Model Dimensions}

While choosing any particular model, following factors need to be carefully examined (Niue, 2008);

1. Order Picking Methods: it is crucial to decide whether the company wants to opt for central warehousing or use store warehouses instead. Typically, central warehousing is an expensive option and is only viable when order generation is high. For low customer density areas, it has been seen that starting distribution using store warehouses is a more feasible option.

2. Delivery and Pricing: companies use both attended and unattended delivery systems. Attended delivery requires the order to be received by the client in person, while unattended delivery is made to certain reception points in 'Reception Boxes'. This increases order fulfillment on average, as the 
hassle of ensuring clients' presence is removed. Many companies following unattended delivery system rent out reception boxes which are placed in certain areas from where clients can pick up their orders. It is a better option for optimal fleet utilization. Furthermore, companies offer discounted delivery days called 'value days' for certain areas. The idea is to prompt customers to arrange for order delivery on days when the delivery man would be servicing a particular area. Discounts are offered for ordering on certain days for people in certain areas, thus facilitating fleet utilization.

3. Customer Retention: one particular problem faced by e-grocers is lack of customer loyalty and low customer retention. Past literature shows that this can be curtailed by offering loyalty programs and club cards. These incentives allow clients to accumulate points and then avail discounts and deals online. Studies have also shown that e-grocers which affiliate with existing and known brands are more likely to retain customers and generate more orders.

4. Management and Expansion: it is advised to have an informed management which knows about the grocery industry in general and egrocery industry in particular. Many such startups have failed owing to lack of knowledge of the management. In a similar vein, it is important for the management to realize that e-grocery is still an uncommon idea, and customer buyin is automatically slow. Aggressive and quick expansions are thus not

\begin{abstract}
advisable. Examples of failed ventures like Webvan and Streamline made the mistake of expanding rapidly without developing a solid customer base, which resulted in their early demise.
\end{abstract}

\section{Operational Model}

Boyer \& Hult, (2005) has suggested an operational model divided into four distribution areas namely, Semi Extended, Fully extended, De-Coupled and Centralized Extended. The features of that model are given below:

Semi Extended: The pickup of grocery orders is done from retail outlets, using of third party to deliver them. It has lower fixed capital investment. Order picking efficiency is low. Indirect delivery results in lower cost and customer convenience

Fully Extended: picking of groceries from retail outlets and using in house fleet to distribute to the customers. It has low capital investment and lower picking efficiency. Delivery costs may be high and so will the customer convenience

De-Coupled: Uses a distribution center but relies on third party for delivery. It has high capital investment but higher picking efficiency, lower distribution costs and customer convenience

Centralized Extended: It is categorized as an extreme strategy, having high investment costs. It uses warehouse. Direct delivery costs are more with higher customer convenience and high picking efficiency.

Table 1 is a summary of the features of order fulfillment modes that were researched by Boyer \& Hult, (2005). 
Table 1: Order Fulfillment Modes

\begin{tabular}{|c|c|}
\hline Store Based & Distribution Centre \\
\hline Semi Extended & De-Coupled \\
\hline $\begin{array}{l}\text { Pick up from retail store } \\
\text { - Low Capital Investment } \\
\text { - Order picking efficiency is low } \\
\text { - Using indirect or third party delivery } \\
\text { - Low delivery cost } \\
\text { - Low customer experience }\end{array}$ & $\begin{array}{l}\text { Use warehouse } \\
\text {-High capital investment } \\
\text {-Order picking efficiency is high } \\
\text { - Using indirect or third party delivery } \\
\text { - Low delivery cost } \\
\text { - Low customer experience }\end{array}$ \\
\hline Fully Extended & Centralized Extended \\
\hline $\begin{array}{l}\text { Pick up from retail store } \\
\text {-Low Capital Investment } \\
\text {-Order picking efficiency is low } \\
\text {-Using in-house delivery } \\
\text {-High delivery cost } \\
\text {-High customer experience }\end{array}$ & $\begin{array}{l}\text { Use warehouse } \\
\text {-High capital investment } \\
\text {-Order picking efficiency is High } \\
\text {-Using In-House delivery } \\
\text {-High delivery cost } \\
\text {-High customer experience }\end{array}$ \\
\hline
\end{tabular}

\section{Last Mile Concept}

Last mile is a metaphor used in supply chain. It is the last stage before the product arrives at the doorstep of the customer from the inventory or fulfillment area (Gevaers, Van de Voorde, \& Vanelslander, 2011). It is the most crucial part of the entire supply chain in case of online grocery shopping (Boyer \& Hult, 2005).

Gevaers, Van de Voorde, \& Vanelslander, (2011) developed a typology by combining the works of Gevaers et al., (2008), Gevaers et al., (2009), Leavit (2008), Madlberger, (2005), Murphy (2006), Punakivi et al., (2001), Van Oosterhout, (2004) and Waltevreden, (2008). Though the typology developed by Gevaers et al., (2011) is commonly applied but it does not represent the specific characteristics of the last mile in an adequate and unequivocal manner. Since Last mile faced three critical issues: a) Home deliveries- consumer not at home, b) lack of critical mass in a given region, due to an inadequate market density or penetration and c) consumers awareness of the environmental impact. To solve such issues, areas offering opportunities for optimizing last-mile efficiency and reducing costs were found to include; consumer service level, security and delivery type, the geographical region, market penetration or density, vehicle fleet and technology and environment. On the basis of detailed analysis on these areas a typology distinguishing between sub flows on the basis of product value was suggested, subdivided into three value-based flows: a) high-value/durable products (such as laptops), b) durable goods of medium value (such as DVDs and books) and c) low to very low unit value (such as groceries or daily consumer goods).

Delivery Models: Apart from deciding on the overall business strategy, an online grocer must also work on functional level strategy. Delivery method plays a pivotal role in operational strategy. One should carefully examine the economics of each option from two angles: the additional gross margin the model will allow to generate and the fulfillment and delivery costs of each model. Furthermore, it was stated that sustaining long-term profitability requires picking 
orders from purpose-built facilities with high degrees of automation. A suggested list of the delivery methods by Wyman, (2014) includes; a) Picking: In store, by retailer, b) Picking: In store, by third party, c) Picking from warehouse or dark stores, d) Delivery: Click and collect, e) Delivery: by retailer and f) Delivery: by third party.

\section{Online Grocery - Why or Why Not It Might Prevail}

Online-only grocery business is a perplex venture as it requires high capital requirements, fulfillment costs, delivery costs and price transparency. Since, online grocers do not trigger impulsive buying thus customer spending can be lower, customers are not open to the idea of having someone else pick fresh food for their family, while some have "need it now" shopping patterns. Thus, the venture stands a chance as well (Wyman, 2014).

Fundamentally, the market share required to break even depends on three major factors: population density - affects cost of the last mile delivery, overall population, affects fixed asset leverage and market price levels determine gross margins that are achievable.

Chu, Chintagunta, \& Cebollada, (2008) analyzed price sensitivity for online shopping. They discovered that demographics of the customers is closely linked to their price sensitivity in online shopping, while the distance of the retail store is inversely proportional to customer price sensitivity. Hence, customers residing in areas where retail stores are far, those customers are more likely to purchase online as compared to their counterparts who reside in areas where retail stores are near.

\section{Methodology}

The research methodology used for this research was qualitative in nature. The diversity of the research lies in the data collected from the extensive literature survey and the analysis of the data gathered in relevance to the Pakistani context.

\section{Conceptual Framework}

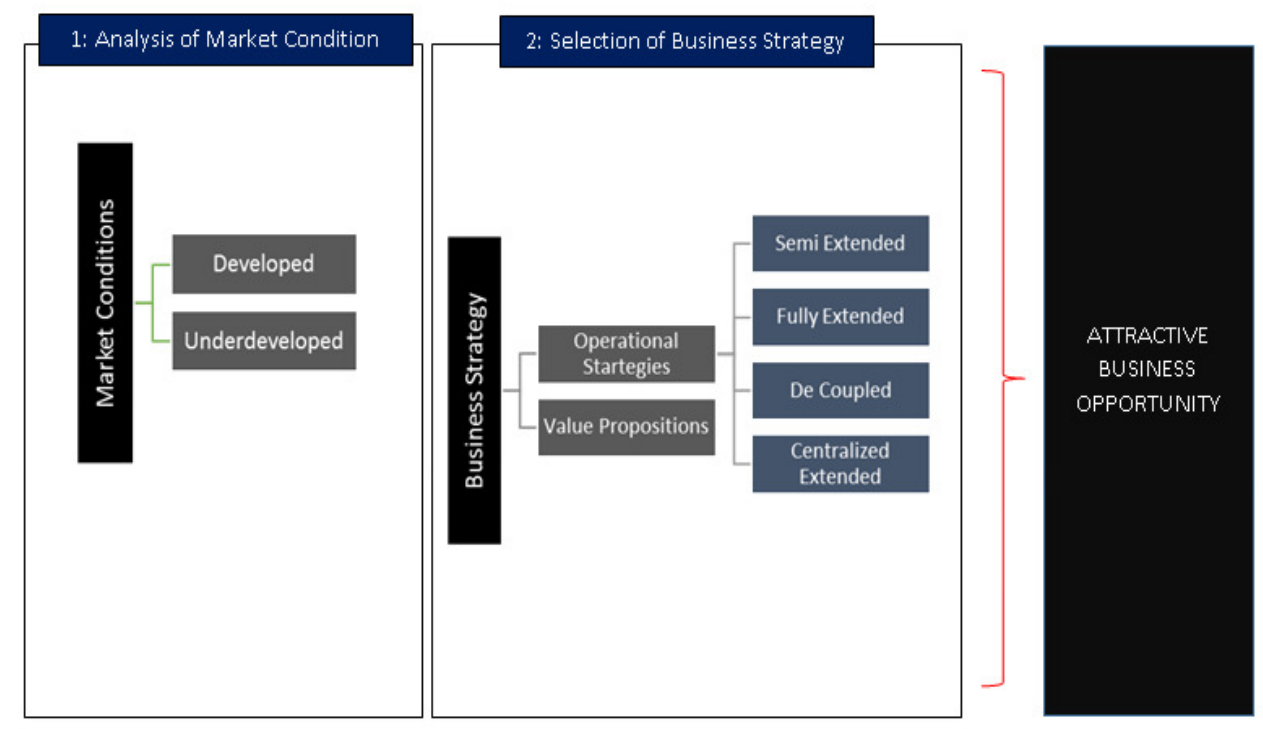

Figure 1: Conceptual Frameworks for Ideal Business Model in Pakistani Market 
After the extensive review of literature, the researchers devised a conceptual frame work based on market conditions and business strategies. The conceptual framework shown in Figure 1 encompasses two main dimensions that a potential online grocer needs to consider to make most of an attractive business opportunity.

The first dimension is the prevalent situation of local market in terms of level of development. By the word 'development' various factors which are being addressed are: resources present in the market, consumer's readiness stage and number of players present in the market. A market of online grocery would be said to be developed if;

- It is made of consumers whose readiness level has been harnessed up to a level where they are accepting the market offer

- Where there are sufficient market players to stimulate competition or a single player that dominates the arena and whose market offering is widely accepted

- Sufficient level of resources is present which can be capitalized by the market players. Resources would include various dimensions such as infrastructure, manpower and logistics

An undeveloped local market would be weak in the aforementioned three criteria. That is, firstly the consumer's readiness level would be low and thus market offerings' acceptance would be low. Secondly, no single market player would be having clear dominance or whatever number of players there might be all of them would be at a nascent stage. Thirdly, the resources required to flourish an online grocery shopping business would be insufficient.

The second dimension of the conceptual framework constitutes of the Business Strategy. Operational Strategy and Value Proposition are two main elements of business strategy which need to be considered by any potential online grocer that intends to flourish its business.

The above mentioned conceptual framework primarily highlights two main relationships;

- Market condition's impact on business strategy

- Impact of value proposition on operational strategies

Firstly, before deciding on the course of the business, i.e. before deciding on the business strategy, a potential online grocer must analyze the prevalent conditions in the local market. A developed local market would require a different game plan altogether than an undeveloped market. Thus, market conditions impact choice of business strategy

The second relationship of prime significance is of operational strategy and value proposition. The conceptual framework implies that whatever value propositions an online grocer intends to pursue, the operational strategy must be carefully designed to bolster the value proposition that needs to be rendered. It should not be the other way round - that is pursuing any of the four operational strategies and then deciding on the value proposition which would be rendered to the consumers. Simply put, the thought process under the business idea must supersede and must take place before taking specific actions which are of operational nature.

Thus, an attractive market opportunity i.e. a successful online grocer, would only be possible if the potential player first analyzes the prevailing scenario in the local market and does so correctly. And then devises a business strategy, in which the value proposition and customer's pain points dominate the selection of operational model. 


\section{Discussion}

Before deciding on the course of the business, i.e. before deciding on the business strategy, a potential online grocer must analyze the prevalent conditions in the local market. A developed local market would require a different game plan altogether than an underdeveloped market. Thus, market conditions impact the choice of business strategy. A detailed analysis of the prevalent market is required which is of primary significance for any player to understand and know whether the market is either developed or underdeveloped, because each case demands a different application of strategies.

The local market for online grocery in Pakistan is largely underdeveloped as of now. The reasons are discussed below;

- The reason lies in the fact that local consumers are not aware of the concept of online grocery as yet. Ventures like Grocia.pk, Khaopiyo.pk, RashanMart.pk, Pakistan grocery service.com are largely unheard. Low scale of operation and weak execution are making such new ventures to work in exile. With no awareness of the platform, Pakistan market is yet to explore a successful venture in this regard. Since, there is no awareness among the consumers thus - the resultant low readiness level to accept such an offering is consequential as well

- Secondly, although there are more than 30 new online grocers currently operating in Pakistan, yet none of them have quite made an impact on the market in terms of dominance. The reason lies in the fact that almost all of them are entrepreneurial start-ups and therefore, do not have large budgets at their disposal to market widely also, this limits their scope of conducting operations. Startups like QnE, RashanLelo and Doorstep are all facing budget constraints and are unable to cater for the market the way they wanted.

- Thirdly, in terms of resources, local market is quite sufficient. The technical resources required for such an offering are quite basic in nature: hence, they are abundantly and easily available. This serves the basic reason why more than 30 startups are operational in Pakistan. However, analytical resources such as tools or background studies for local market are not widely available and accessible for an entrepreneur.

Now, that it has been established the fact that the local market is undeveloped, the question arises what business strategy is the most suitable to adopt in the local market? In the Literature Review, four specific operational strategies namely; Semi Extended, Fully Extended, De Coupled and Centralized Extended were discussed (refer to Table 1).

After the analysis it was learned that the most suitable operational model for local market is Fully Extended. One of the argument for suggesting this model is that as mentioned above, it requires low capital and provides high customer experience. Both of these things complement the prevalent state of the undeveloped state of the market that we have. Since, most of the online grocers are entrepreneurs with limited budgets to invest - this model works well for them. Not only the capital investment is low - but it also ensures high customer experience. This high customer experience is rendered primarily because of the following main reasons;

- When a grocer has an option to pick from multiple retail points, he can offer a wide variety of products to the customers as opposed to carrying a fixed inventory. The products involved in grocery shopping are of varying price points, 
SKUs and variants. Stocking all such varieties in a warehouse and that too in a market that has not fully accepted the concept of online grocery shopping is a risky operational decision.

- The holding and warehousing costs of the inventory would be none (as opposed to Centralized Extended, which imposes high inventory and holding cost due to warehousing). Making such a huge investment in the initial phase does not seem a right business move. In ecommerce, online retailers often operate on losses for years until their breakeven is achieved. (Case in point: Amazon and Rocket Internet). This implies that the higher the investment, the longer the time to break even. And needless to imply that as long as the achievement of breakeven is delayed, the profits are not materialized which further puts the business operation at risk.

- The delivery is in-house, which means that the online grocer has full control over the delivery and can monitor it vigilantly. Delivery is the one of the few significant avenues where the customer comes in direct contact with the brand - and if that is not carefully handled then it would lead to an adverse customer experience. Thus, in this way the high delivery cost is justified because it is letting the online grocer control the interaction between the service and the customer. (As opposed to Semi Extended, where the function of delivery is outsourced. Even though, it translates into low costs but it also means losing control over the interaction that takes places between the consumer and grocer when the actual delivery of goods takes place. Bad experiences in service industry are seldom forgotten and more than often lead into bad word of mouth). Another point of significant importance to emphasize on customer experience is the fact that our local market is at a nascent stage and the online grocers need to convince the customers of the offering. Thus, ensuring positive experiences becomes a necessity for any player that intends to develop this client base.

One might argue that this model leads to low order picking efficiency. The counter argument for this statement is simple - not every operational model is everything in every situation, i.e. one needs to decide on what the priorities are given the prevalent market conditions. Secondly, since the delivery is in-house in this strategy - that's how a company can keep a tap on its fleet of riders or vans and improve its efficiency by using technologies - such as, using GPS enabled delivery vans or partnering with retail stores and installing software to keep a track of inventory available with them.

The other part of the business strategy depends on deciding the value proposition for the business. The value proposition embodies the 'benefit' which the ultimate consumers will have. This benefit can be actual or perceptual, but anyhow it must be as such that is valued by the target audience and carries relevance for them.

Few of the key value propositions that an online grocer can offer can be convenience, good quality, variety in products or exceptional price points. While deciding on the value proposition, an online grocer must take the consumer's pain points and preferences into account. For instance, consumer's do not like paying delivery fees or waiting for deliveries while other times the consumers are not even ready to make the switch (which is the prevalent case in local market).

Another point of consideration is that value proposition for any online grocery store must 
be of novel nature. If the value proposed is similar as to what is being offered by brick and mortar stores then chances are the potential consumers would not see much difference and might not make the effort to switch their buying behavior.

Dawes \& Nenycz-Thiel, (2014), findings revealed that the customers cross purchase from different retail outlets online and offline. Their findings further confirmed that the customers who shop online also shop in offline stores. However, the customer loyalty is inclined more towards the brand and remains similar even if that brand is purchased from a different retailer. When it comes to brand loyalty, Danaher, Wilson, \& Davis, (2003), analyzed that when customers opt to purchase a brand online they refer to its quality by the brand name. Furthermore, strong brands tend to do well even in online purchase as compared to their weaker counterparts.

\section{Online grocery Ventures in Pakistan}

Online grocery is an unexplored but interesting element in Pakistan's expanding e-commerce landscape. While on one side physically exploring huge cash ' $\mathrm{n}$ ' carry stores is a popular way to shop, the growth in online grocery stores indicates some interest in the market for those who wish to evade that hassle and order goods at the click of a button. For this 30 new startups have already been launched and Pakistan is getting overloaded with the new ventures (Hanif, 2016)

With the sudden tilt towards online grocery, market space is getting competitive and has almost become the battlefield for the new ventures. As per our analysis, Startups like Grocia.pk, Khaopiyo.pk, Rashanmart.pk, Pakistangroceryservice.com,

www.giftstopakistan.com, Rashanwala.pk, www.rfeen.com, www.consumernewspk, Meridukan.pk, thecsspoint.com and many more have failed to make any impact in the market. One reason stems from the fact that these startups are merely a website with no proper business idea. Moreover many of these operate on a very low scale due to lack of resources. Since the technical expertise are not very difficult to find, many small players have invaded the market but only few have been able to make a mark.

Apart from these small startups, there are considerable big ventures that have entered the market with an aim to lead the online grocery platform and also to inculcate the online buying habit in the consumers. For a market like Pakistan's, online shopping is relatively a new idea. Though ventures like Kaymu, Daraz, Food panda, EatOye, Sukoon.pk, to name a few, have done an impeccable job to build the trust of consumers in online buying, still a lot of work needs to be done. As far as online grocery is concerned the history of this model lies just a couple of years back.

Trust is an important factor when it comes to online shopping: Mortimer, Hasan, Andrews, \& Martin, (2016) observed that the customers who experience satisfactory online transactions tend to develop trust for that online platform and channel. By satisfactory transaction, it is implied that the customers' demands are met as expected or the retailer has surpassed those demands and hence gained the trust of the customer.

Park, Iyer, Smith, Iyer, \& Smith, (1989) identified certain shopping behaviors that increase the store's revenue. The behaviors include: increase in unplanned buying, low rate of purchase failure, low postponement of purchase and improvement in the quality of purchase volume decisions. They further advice the managers to make strategies that do not confuse the customers, like do not make frequent changes in the shelf arrangement or placement of product information on the website, as it confuses the customers and also wastes their time in searching for their desired product. Hence, customer is most likely to leave without making any purchase.

It is concluded that the Startups like Cart.pk, RashanLelo, AaramShop.pk, and Taza Mart entered the Pakistan market with 
considerable experience and distinctive business model. Though in Pakistan none of them have emerged as the clear winner but these startups has surely made their presence felt. Reason being, all the ventures are of already established players, with good budgets, strong sense of consumer habits and also the goodwill of their Parent company.

Analyzing each one of them and their business model will give a clear view of how these ventures are working in Pakistan. Since all the models cannot be taken into perspective, a short competitive landscape can depict the entire picture.

Analysis of the Pakistani market makes it clear that unlike other niche markets, the online grocery sector has seen a sudden explosion in the last two years. The year 2013 saw the launch of several such startups, including Aaram Shop, which is an Indian franchise, and RashanLelo, set-up by five friends with expertise in different fields. Since then, nearly a dozen such websites have sprung up, such as CartPk, MyCart, PakistanGrocery, BigBasket, GoMart, Doorstep, QuickNEasy, and TazaMart to name a few. But the majority of these businesses are based in Karachi, with only a couple catering for other urban centers like Lahore and Islamabad. This shows that there are several untapped markets waiting to be exploited. Pakistan online market has a lot of potential and this trend will keep on rising

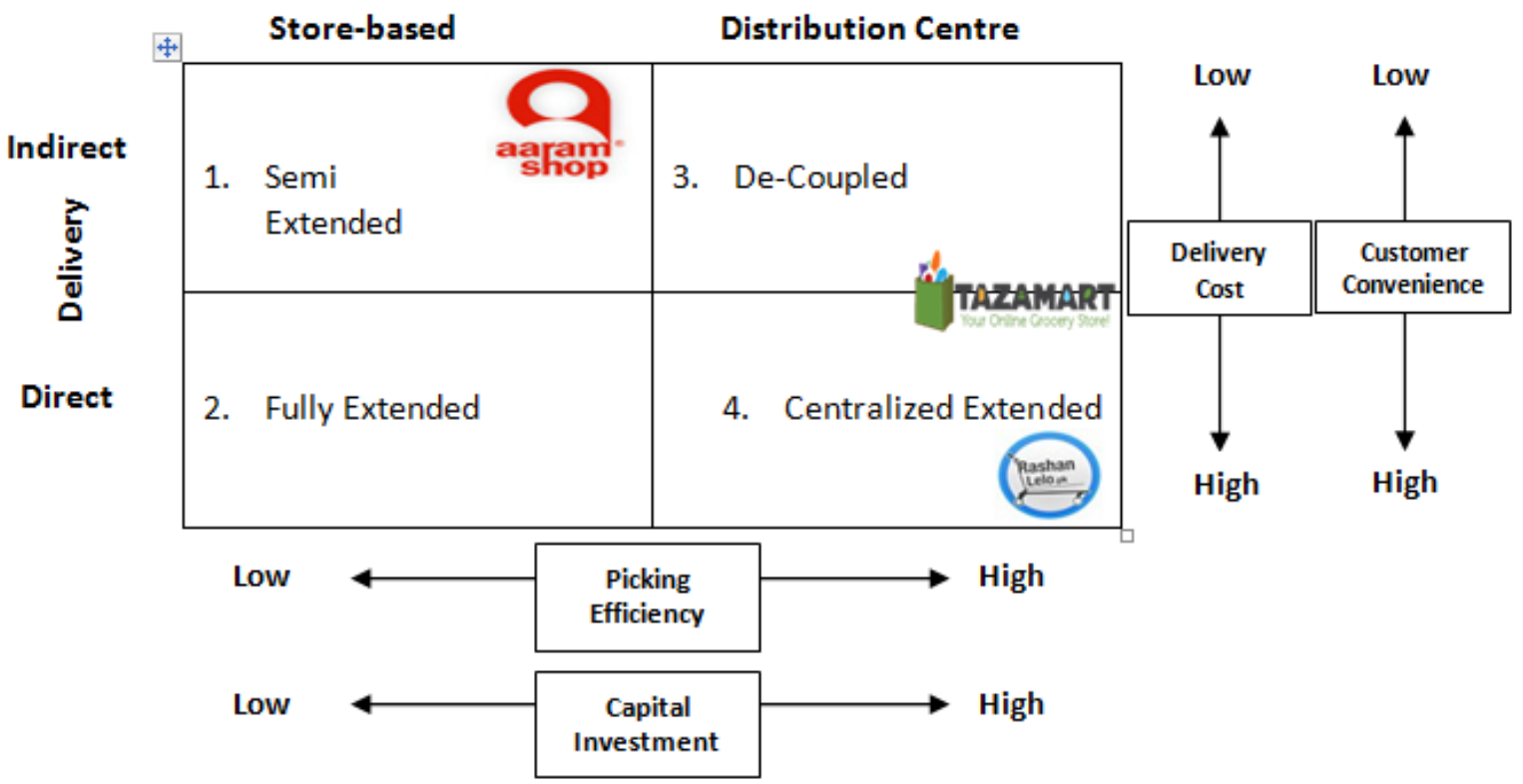

Figure 2 Modes of Delivery (Operational Model) and Positioning of Pakistani Online Grocery Startups

\section{Case 1: AaramShop Pakistan - Neighborhood Model}

AaramShop is an Indian based venture that started its operations in Pakistan in October
2014 (Baloch, 2014). It has adopted the neighborhood model and works in collaboration with other retailers also known as 'kiryanay ki dukaanein'. When a customer places an order online, the retailer situated nearest to the customer delivers the 
groceries to the customer or AaramShop employees collects and delivers the order at the doorstep. AaramShop Pakistan has approximately 600 retailers in the network that covers all the areas in Karachi and Lahore (Arshad, 2015).

Retailers that are associated with AramShop are given a portal access through which they update product details and their list time to time. The organizations do not charge any commission for their basic service which includes helpline and web presence. However they do charge between Rs. 1000 \& Rs. 5000 as their retainer fee. Additional charges are applied for any special service adopted by the retailer which mainly includes promotional SMS, mobile app or special email marketing campaigns for the retailer.

Partnership tie-ups with FMCGs such as L'Oreal, Searle Pakistan, Shan Foods and Unilever have become the main source of revenue for AramShop. These tie-ups include promotion of the brand to AramShop customers. Such as special promotions on their website, neighborhood marketing whereby promotional brochures are put in every delivery bag that is sent to the customer. Digital sampling is also done through AramShop page, where customers fill the form to get free samples. The data acquired are then passed on to the respective brand teams (Arshad, 2015)

Minimum delivery orders range between Rs. 500 \& Rs. 1,000 and the main payment method is Cash on Delivery (COD) which is the most popular mode of payment. AramShop's competitive advantage lies in their delivery system, which is guaranteed within a maximum of two hours if the order is placed before 6:00 p.m.; if placed after 6:00 p.m. the delivery is done the next morning.

\section{Case 2: RashanLelo - Inventory centric model}

RashanLelo is a Karachi based venture started in December 2013. The company maintains its own inventory and has no direct connection with retailers. They buy in bulk from the wholesalers and sell them at market price. Presently RashanLelo has no association/partnership with any FMCGs and has no plans to do so in the future. The company wants to have a steady flow and aims to have a customer base of 1,500 per month before initiating brand Tie-ups. (Arshad, 2015)

RashanLelo makes profit typically from the price margin, but what outstands them is the fact that their product prices remain the same and not vary from retailer to retailer which usually happens in retailer centric models. The product prices stay consistent and customers do not face any price change in the final bill.

The minimum order amount is fixed i.e. Rs. 5,000 that will reduce to 3500 in the near future. The order is delivered the subsequent day of the order at the customer's preferred delivery time.

\section{Case 3: TazaMart}

TazaMart is an Arpatech venture which is famous in Pakistan for its venture EatOye. TazaMart entered in to the market with its easy-to-use website and a responsive customer support team. Their value proposition promises convenience and efficiency, but what gives TazaMart the edge over others is their variety of products. With a response time of 15 minutes and a promise to deliver within 6 hours of order placement or the next day if the order is placed after 6 $\mathrm{pm}$ this venture is increasing its pace.

It influences consumers by offering a lower price, giving them more variety, and timely delivery. TazaMart maintains its own inventory as of now which is currently leading to low variety but the company has plans to come up with perishable items, price comparison option and great variety in the near future. Registered users of TazaMart have their order history stored, and they can activate the repeat option which would automatically add the previously purchased items to their cart when placing their order. 
TazaMart has no limit on a minimum order; they start free delivery on purchase of Rs. 1, 000 and more. They have acquired "Forrun by Arpatech" to do the last mile logistics for TazaMart. Forrun is an Arpatech venture which will also see the supply chain of TazaMart. With this TazaMart is moving toward centrally extended model with their own delivery and warehouse operation (MoreDesk, 2016).

\section{Limitations And Future Research}

The discussion is restricted to the Pakistani market, but the model identified can be used globally for online grocery startups. We have not covered the consumer aspect of online retail in this paper and which can be a point of research in future. Empirical evidence based on consumer interviews and discussions with managers/businessmen of online grocery venture can also be topic of future researches in this regards.

\section{References}

1. Ahmed, J. (2015, October 19). The encouraging future of e-commerce in Pakistan. Retrieved June 26, 2016, from http://tribune.com.pk/story/975430/theencouraging-future-of-e-commerce-inpakistan/

2. Arshad, A. (2015, March 1). Online and onwards. Retrieved June 26, 2016, from http://aurora.dawn.com/news/1140744

3. Baloch, F. (2014, March 9). Online grocery shopping looking to find a way in. Retrieved July 9, 2016, from http://tribune.com.pk/story/680751/online -grocery-shopping-looking-to-find-a-way-in/

4. Boyer, K. K., \& Hult, G. T. M. (2005). Extending the supply chain: Integrating operations and marketing in the online grocery industry, 23, 642-661. http://doi.org/10.1016/j.jom.2005.01.003
5. Breugelmans, E., Campo, K., \& Gijsbrechts, E. (2007). Shelf sequence and proximity effects on online grocery choices. Marketing Letters, 18(1-2), 117-133.

6. Castaneda, L., Villegas, N. M., \& Müller, H. A. (2014). Personalized Web-Tasking Applications: An Online Grocery Shopping Prototype. In 2014 IEEE World Congress on Services (pp. 24-29). IEEE. Retrieved from http://ieeexplore.ieee.org/xpls/abs_all.jsp?a rnumber $=6903239$

7. Chu, J., Chintagunta, P., \& Cebollada, J. (2008). A Comparison of Within-Household Price Sensitivity Across Online and Offline Channels. Marketing Science, 27(2), 283-299.

8. Dada, H. (2016, January 27). Online grocery shopping becoming famous in Pakistan - More. Retrieved from http://www.moremag.pk/2016/01/27/onli ne-grocery-shopping-in-pakistan/

9. Danaher, P. J., Wilson, I. W., \& Davis, R. A. (2003). A comparison of online and offline consumer brand loyalty. Marketing Science, 22(4), 461-476.

10.Dawes, J., \& Nenycz-Thiel, M. (2014). Comparing retailer purchase patterns and brand metrics for in-store and online grocery purchasing. Journal of Marketing Management, 30(3-4), 364-382.

11.De Kervenoael, R., Yanık, S., Bozkaya, B., Palmer, M., \& Hallsworth, A. (2016). Tradingup on unmet expectations? Evaluating consumers' expectations in online premium grocery shopping logistics. International Journal of Logistics Research and Applications, 19(2), 83-104.

12.Gevaers, R., Van de Voorde, E., \& Vanelslander, T. (2011). Characteristics and typology of last-mile logistics from an innovation perspective in an urban context. City Distribution and Urban Freight Transport: Multiple Perspectives, Edward Elgar Publishing, 56-71. 
13.Hanif, A. (2016, March 7). Do Pakistan's online grocery stores deliver what they promise? We find out. Retrieved July 9, 2016, from http://www.dawn.com/news/1242498

14.Hans, P. P. (2013). Selling groceries online is catching up in India. Retrieved July 9, 2016, from http://www.businesstoday.in/moneytoday/ smart-spending/online-grocery-shoppingvegetables-new-trend-inindia/story/197141.html

15.Hansen, T. (2005). Consumer adoption of online grocery buying: a discriminant analysis. International Journal of Retail \& Distribution Management, 33(2), 101-121.

16.Hong, W., Thong, J. Y., \& Tam, K. Y. (2004). The effects of information format and shopping task on consumers' online shopping behavior: A cognitive fit perspective. Journal of Management Information Systems, 21(3), 149-184.

17.Mazhar, A. (2014). Pakistan's Youth Bulge: Human Resource Development (HRD) Challenges: Islamabad Policy Research Institute. Retrieved June 26, 2016, from http://www.ipripak.org/pakistans-youthbulge-human-resource-development-hrdchallenges/\#sthash.ymlpRqDi.dpbs

18.Milkman, K. L., Rogers, T., \& Bazerman, M. H. (2010). I'll have the ice cream soon and the vegetables later: A study of online grocery purchases and order lead time. Marketing Letters, 21(1), 17-35.
19.Niu, T. (2008). Strategies for success in the e-grocery industry. Retrieved from http://scholarworks.rit.edu/theses/388/Onl ine grocery shopping looking to find a way in. (2014, March 9). Retrieved July 9, 2016, from http://tribune.com.pk/story/680751/online -grocery-shopping-looking-to-find-a-way-in/

20.Park, A. C. W., Iyer, E. S., Smith, D. C., Iyer, E. S., \& Smith, D. C. (1989). The Effects of Situational Factors on In-Store Grocery Shopping Behavior: The Role of Store Environment and Time Available for Shopping. Journal of Consumer Research.

21.Pozzi, A. (2012). Shopping cost and brand exploration in online grocery. American Economic Journal: Microeconomics, 4(3), 96120.

22.Pozzi, A. (2013). The effect of Internet distribution on brick-and-mortar sales. The RAND Journal of Economics, 44(3), 569-583.

23.Retail, G. T., \& Survey, C. (2015). Total Retail 2015 (February).Statistica. (2016). ECommerce. Retrieved June 26, 2016, from https://www.statista.com/markets/413/ecommerce/U.S. Census Bureau News. (2016). Retrieved from http://www.census.gov/retail/mrts/www/d ata/pdf/ec_current.pdf

24.Wharton. (2015). Online Groceries in India: Will Consumers Bite? Retrieved July 9, 2016, from http://knowledge.wharton.upenn.edu/articl e/online-groceries-in-india-will-consumersbite/ 